\title{
Defects Induced Room Temperature Ferromagnetism in ZnO Thin Films
}

\author{
Xiao Zhang, Wei Zhang, Xinghua Zhang, Xuewen Xu, Fanbin Meng, and C. C. Tang \\ School of Materials Science and Engineering, Hebei University of Technology, Tianjin 300130, China \\ Correspondence should be addressed to Xiao Zhang; zhangxiaonk@gmail.com and C. C. Tang; tangcc@hebut.edu.cn
}

Received 2 December 2013; Accepted 27 December 2013; Published 19 February 2014

Academic Editor: Shoubao Zhang

Copyright (C) 2014 Xiao Zhang et al. This is an open access article distributed under the Creative Commons Attribution License, which permits unrestricted use, distribution, and reproduction in any medium, provided the original work is properly cited.

Polycrystalline $\mathrm{ZnO}$ thin films are prepared by the co-sputtering method under different oxygen partial pressures. Films deposited in pure argon gas exhibit ferromagnetism, whereas other films deposited under different oxygen partial pressures are diamagnetism. XPS results show the presence of $\mathrm{Zn}$ interstitial and oxygen vacancy in all of samples. Further analysis indicates that $\mathrm{Zn}$ interstitial may play an important role in triggering magnetic order on the undoped $\mathrm{ZnO}$ thin films by inducing an alteration of electronic configuration.

\section{Introduction}

ZnO-based dilute magnetic semiconductors (DMSs) have attracted intense interests due to their potential applications in spintronic devices [1]. Room temperature (RT) ferromagnetism (FM) has been reported theoretically and experimentally in magnetic transition metal doped $\mathrm{ZnO}$ nanoparticles and thin films [2-7]. However, several works pointed out that the transition metal dopants are not essential in the observed ferromagnetism. For instance, the results of X-ray magnetic circular dichroism spectra showed that the magnetism in $\mathrm{Mn}$ doped $\mathrm{ZnO}$ nanoparticle and thin films is critically sensitive to defects other than the transition metal dopants themselves [8] and bulk $\mathrm{ZnO}$ doped with $\mathrm{Co}, \mathrm{Mn}$, or $\mathrm{Cr}$ shows paramagnetism $[6,9,10]$. Meanwhile, RT FM was observed in nonmagnetic ion doped $\mathrm{ZnO}$ thin films and nanoparticles [11-13] and even undoped $\mathrm{ZnO}$ films [14-17], nanoparticles $[18,19]$, or partially oxidized $\mathrm{Zn}$ nanowires [20, 21], which indicates that the RT FM observed in $\mathrm{ZnO}$ matrix may be intrinsic. It is restricted to some defect-rich regions, such as the surface, interface, and grain boundary, not uniform throughout the samples [22]. On the other hand, the indirect exchange interaction models such as Zener/RudermanKittel-Kasuya-Yosida (RKKY)-type exchange, double- and super-exchange, F-center-mediated bound magnetic polaron models, are hard to explain the observed RT FM induced by only few percent of magnetic ions. Thus, the intrinsic defects should be important on the FM order in $\mathrm{ZnO}$-based DMSs. However, which kinds of defects play an important role, how the defects facilitate the magnetic coupling, and how to control these defects are still under intensive debate. Some reports demonstrated that RT FM could stem from the lattice defects such as oxygen vacancy $\left(V_{\mathrm{O}}\right)$ or $\mathrm{Zn}$ interstitial $\left(\mathrm{Zn}_{i}\right)$ in pure $\mathrm{ZnO}$ thin films, nanoparticles, and nanowires [17, 23-26]. Straumal et al. [27] demonstrated that FM only appears if the ratio of grain-boundary area to grain volume exceeds a certain threshold value. Sanchez et al. [28] predicted that varying the hydrogen density on the $\mathrm{ZnO}$ (0001) surface can achieve reversible switch of surface FM. More interestingly, even absorbing certain organic molecules can induce ferromagnetic-like behavior in undoped $\mathrm{ZnO}$ nanoparticles [29]. These results challenge the understanding of the origin and mechanism of FM.

So far, although lots of works have been carried out to explore the origin of RT FM in undoped $\mathrm{ZnO}$, the results are far from convincing and even some of the results are inconsistent, partly because $\mathrm{ZnO}$ is a semiconducting material with many species of native defects with quite a few of them behaving as shallow donors. Now, it is known that the native defects depend strongly on preparation methods and conditions. $\mathrm{ZnO}$ materials prepared by various methods from different 
groups generally show significant differences in physical properties including native defect/impurity species and density, mobility, and crystallinity. When these $\mathrm{ZnO}$ materials are employed for DMSs study, it is not a surprise that distinct results were reported even with similar conditions. Therefore, it is the most important to elucidate the effect of specific film-growth conditions. In this study, polycrystalline $\mathrm{ZnO}$ films were fabricated under different oxygen partial pressure $\left(P_{\mathrm{O}_{2}}\right)$. The experimental results show that the only RT FM observed in $\mathrm{ZnO}$ film deposited under pure Ar and saturated magnetization is $0.89 \mathrm{emu} / \mathrm{cc}$, while other samples deposited under Ar and $\mathrm{O}_{2}$ mixture are diamagnetism. After depositing a single $\mathrm{Zn}$ layer on the magnetic film and annealing the sample at high temperature, the saturated magnetization significantly increased to $1.62 \mathrm{emu} / \mathrm{cc}$. These results suggest that the $\mathrm{Zn}$ interstitial may be a response to the origin of FM order in pure $\mathrm{ZnO}$ thin films.

\section{Experiments}

A series of polycrystalline $\mathrm{ZnO}$ films were fabricated by RFsputtering $\mathrm{ZnO}$ (99.99\%) targets in $\mathrm{Ar}$ (99.999\%) and $\mathrm{O}_{2}$ $(99.999 \%)$ mixture at room temperature. The base pressure of the chamber was better than $1 \times 10^{-5} \mathrm{~Pa}$ before deposition and the total pressure for sputtering was kept at $2.0 \mathrm{~Pa}$. The RF-sputtering power of $\mathrm{ZnO}$ target was kept at $260 \mathrm{~W}$. The films were deposited on glass and kapton substrates for the measurements of structural and transport properties, respectively. To eliminate the spurious magnetic data, the samples and polymer tweezers were cleaned with acetone prior to measurement. The films thickness was kept at $200 \mathrm{~nm}$. The microstructure of the films was characterized by X-ray diffraction pattern (XRD) with $\mathrm{Cu} \mathrm{K}_{\alpha}$ radiation $(\lambda=0.15418)$ using $X^{\prime}$ Pert PRO machine. The composition and chemical states of $\mathrm{ZnO}$ thin films were examined by $\mathrm{X}$-ray photoelectron spectroscopy (XPS) and auger electron spectroscopy (AES) using Physical Electronic Spectrometry machine. The DC electrical resistivity measurements were measured using a conventional four-probe method performed in a Quantum Design PPMS. The magnetization measurements were carried out using a Quantum Design vibrating sample magnetometry.

\section{Results and Discussion}

Figure 1(a) shows the XRD pattern of the $\mathrm{ZnO}$ polycrystalline samples fabricated under different oxygen partial pressure $\left(P_{\mathrm{O}_{2}}\right)$. The results indicate that all samples have highly $(001)$ preferred orientation in contrast to the standard diffraction pattern of wurtzite $\mathrm{ZnO}$. The particle size can be derived from the Scherrer formula [30]:

$$
D_{\mathrm{hkl}}=\frac{0.9 \lambda}{\beta \cos \theta},
$$

where $D_{\text {hkl }}$ is the particle size along (hkl) direction, $\beta$ is the full width at half maximum (FWHM) of the XRD peak, $\lambda=0.154058 \mathrm{~nm}$ is the wavelength of $\mathrm{Cu} \mathrm{K}_{\alpha}$ radiation, and $\theta$ is the Bragg angle. Figure 1(b) shows the relation between obtained particle size using the FWHM of (002) peaks and $P_{\mathrm{O}_{2}}$. It can be seen that there is not monotonic dependence of particle size on the $P_{\mathrm{O}_{2}}$. At low $P_{\mathrm{O}_{2}}$, the particle size increases with increasing $P_{\mathrm{O}_{2}}$, reaches the maximum value at $P_{\mathrm{O}_{2}}=1 \mathrm{~Pa}$, and then decreases to $42.7(9)$ at $P_{\mathrm{O}_{2}}=1.5 \mathrm{~Pa}$. With the $P_{\mathrm{O}_{2}}$ increasing, the particle size of the $\mathrm{ZnO}$ thin films tends to be a constant.

The composition and chemical states of the $\mathrm{ZnO}$ thin films deposited under $P_{\mathrm{O}_{2}}=0 \mathrm{~Pa}$ and $P_{\mathrm{O}_{2}}=2 \mathrm{~Pa}$ are further investigated by XPS analysis. Samples were etched by $\mathrm{Ar}^{+}$bombardment $\left(5 \times 10^{5}\right.$ Torr $)$ for $5 \mathrm{~min}$ to examine the intrinsic chemical state of each element in the films. A broad scan survey spectrum indicates that only $\mathrm{Zn}, \mathrm{O}$, and $\mathrm{C}$ elements exist and no other detectable contaminated element above $0.1 \%$ exists in the $\mathrm{ZnO}$ samples. As shown in Figure 2(a) the peak positions of $\mathrm{Zn} 2 p_{1 / 2}$ and $\mathrm{Zn} 2 p_{3 / 2}$ are similar in both samples. Comparing the XPS standard spectra of $\mathrm{Zn} 2 p$ [30], it is concluded that the valence state of $\mathrm{Zn}$ element is +2 . On the other hand, the peaks of $\mathrm{Zn} 2 p_{3 / 2}$ in both samples exhibit slight asymmetry. Islam group has analyzed the $\mathrm{Zn}$ $2 p_{3 / 2}$ peak of $\mathrm{ZnO}$ thin film systematically and attributed this kind of asymmetry of $\mathrm{Zn} 2 p_{3 / 2}$ peak to the existence of excess zinc in the films [31]. No such asymmetry is observed for hydrogen-annealed pure $\mathrm{ZnO}$ films. But the exact nature of the distribution of $\mathrm{Zn}$ in the $\mathrm{ZnO}$ matrix remains under investigation. In order to confirm the existence of zinc in the films, AES measurements were carried out. Figure 2(b) presents a $\mathrm{Zn}\left(\mathrm{L}_{3} \mathrm{M}_{45} \mathrm{M}_{45}\right)$ AES signal of the $\mathrm{ZnO}$ samples deposited under $P_{\mathrm{O}_{2}}=0 \mathrm{~Pa}$ and $P_{\mathrm{O}_{2}}=2 \mathrm{~Pa}$. The major peaks at $264.2 \mathrm{eV}$ are considered to be associated with $\mathrm{Zn}^{2+}$ in $\mathrm{ZnO}$ matrix. The minor one at $261.2 \mathrm{eV}$ is due to $\mathrm{Zn}$ of metallic $\mathrm{Zn}$ or $\mathrm{Zn}_{i}$ in $\mathrm{ZnO}$ matrix lattice. It can be seen that the peak intensity at $261.2 \mathrm{eV}$ for the sample deposited under $P_{\mathrm{O}_{2}}=0 \mathrm{~Pa}$ is significantly larger than that for sample prepared under $P_{\mathrm{O}_{2}}=2 \mathrm{~Pa}$. It implies that more metallic $\mathrm{Zn}$ or $\mathrm{Zn}_{i}$ can be generated under oxygen-deficient atmosphere.

Deeper insight into the chemical states of oxygen is achieved through the analysis of the $\mathrm{O} 1 s$ peaks of $\mathrm{ZnO}$ polycrystalline samples deposited under $P_{\mathrm{O}_{2}}=0 \mathrm{~Pa}$ and $P_{\mathrm{O}_{2}}=$ $2 \mathrm{~Pa}$, as shown in Figure 3. The broad and asymmetric $\mathrm{O} 1 \mathrm{~s}$ peaks could be consistently fitted by a Gaussian function to separate the multicomponent oxygen species, which centered at $530.0 \pm 0.1 \mathrm{eV}, 531.5 \pm 0.1 \mathrm{eV}$, and $532.3 \pm 0.1 \mathrm{eV}$, respectively. The component on the low binding energy side of the $\mathrm{O} 1 \mathrm{~s}$ at $530.0 \pm 0.1 \mathrm{eV}$ is attributed to $\mathrm{O}^{2-}$ ions in wurtzite structure of hexagonal $\mathrm{Zn}^{2+}$ ion array, surrounded by $\mathrm{Zn}$ atoms with their full complement of the nearest neighboring $\mathrm{O}^{2-}$ ions [32]. In other words, the intensity of this component is the indicator of the amount of oxygen atoms in a fully oxidized, stoichiometric surrounding. The medium binding energy component at $531.5 \pm 0.1 \mathrm{eV}$ may partially be associated with $\mathrm{O}^{2-}$ ions that are in oxygen-deficient regions within the matrix. Thus, the variation of the relative intensity ratio of medium component to total $\mathrm{O} 1 s$ may be connected in part to the variations in the concentration of oxygen vacancies. It can be seen that this ratio for the sample prepared without $\mathrm{O}_{2}$ is remarkably larger than the sample deposited under $P_{\mathrm{O}_{2}}=2 \mathrm{~Pa}$. It is consistent with AES results of $\mathrm{Zn}$; that is, 


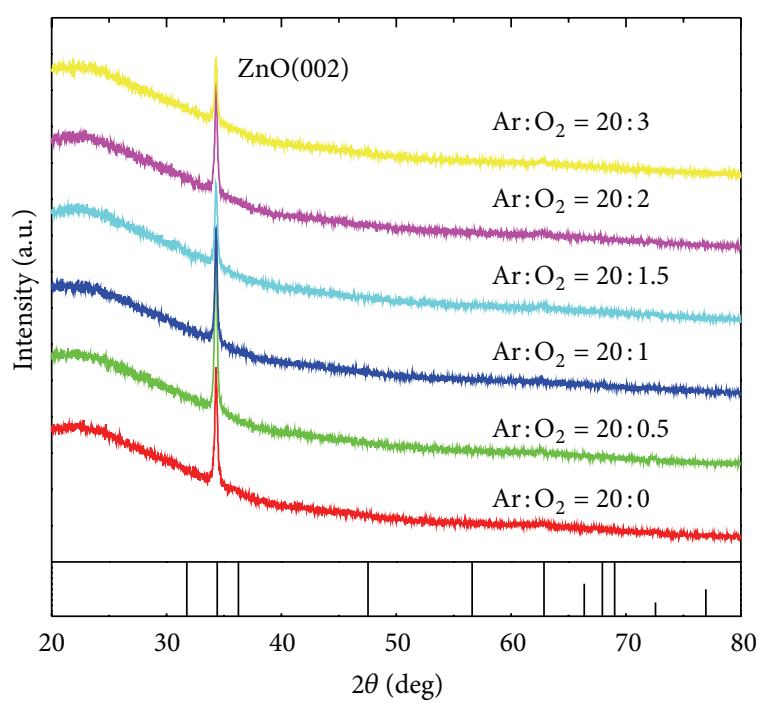

(a)

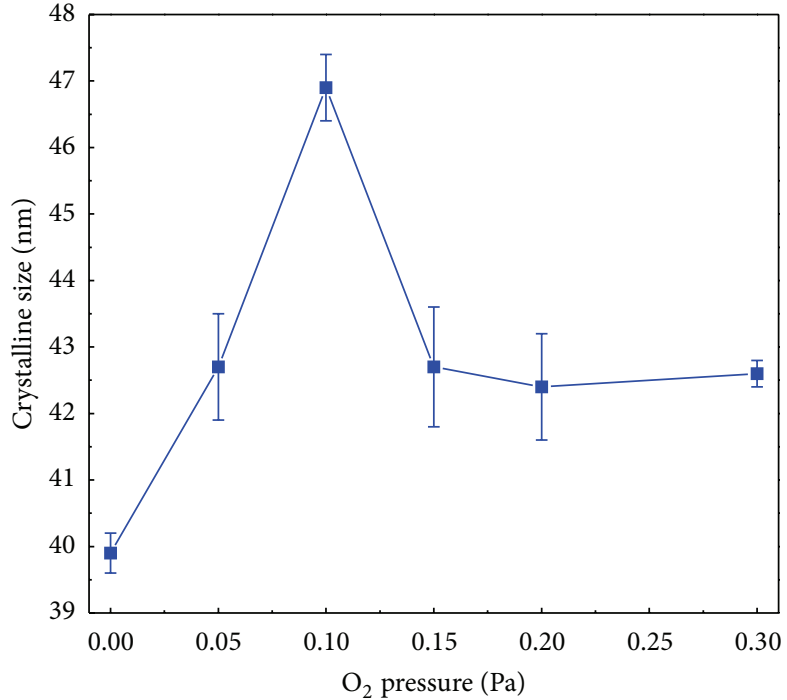

(b)

FIGURE 1: (a) XRD patterns of ZnO polycrystalline thin films deposited under different oxygen partial pressure; (b) the average grains diameters as a function of oxygen partial pressure estimated by the Scherrer equation.

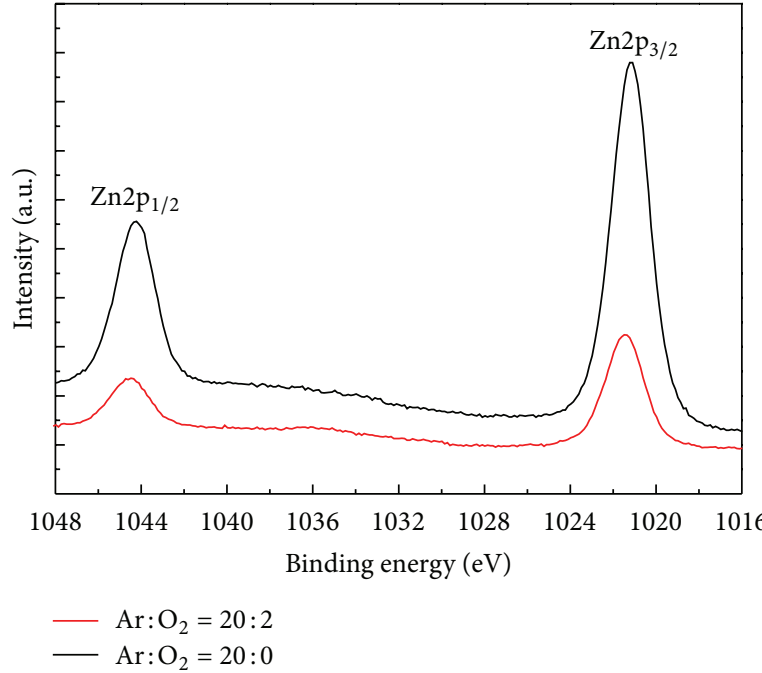

(a)

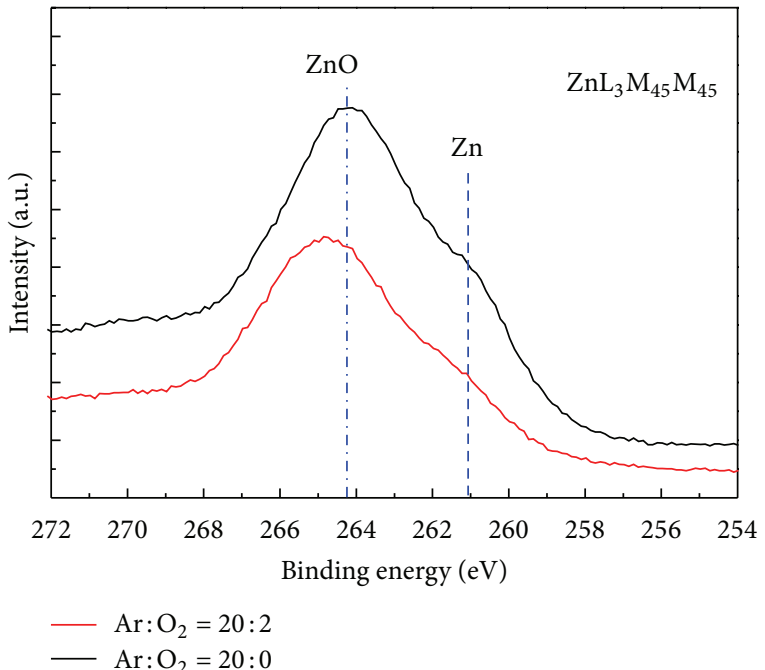

(b)

Figure 2: (a) XPS data of Zn $2 p$ and (b) AES data of Zn LMM in ZnO films deposited under $P_{\mathrm{O}_{2}}=0 \mathrm{~Pa}$ and $P_{\mathrm{O}_{2}}=2 \mathrm{~Pa}$.

without $\mathrm{O}_{2}$, more $\mathrm{Zn}_{i}$ and $V_{\mathrm{O}}$ appear when compared to the sample deposited under $\mathrm{O}_{2}$. Finally, the appearance of the high binding energy component at $532.3 \pm 0.1 \mathrm{eV}$ indicates the presence of loosely bound oxygen in the $\mathrm{ZnO}$ films belonging to specific species, such as adsorbed $\mathrm{H}_{2} \mathrm{O}$ or adsorbed $\mathrm{O}_{2}$, which is difficult to remove by just increasing $P_{\mathrm{O}_{2}}$ during deposition process.

Figure 4 shows magnetization loops of $\mathrm{ZnO}$ films deposited under different $P_{\mathrm{O}_{2}}$. The applied magnetic field was parallel to the surface of the sample. The data in the main figure is $M-H$ curves before the subtraction of the diamagnetic signal of samples, which indicates the sample prepared under $P_{\mathrm{O}_{2}}=0 \mathrm{~Pa}$ shows RT FM. Upper inset of Figure 3 obtained from subtracting the saturated linear parts of the measured signal shows typical hysteresis behaviors and the saturated magnetization is $0.89 \mathrm{emu} / \mathrm{cc}$. However, other samples deposited under different oxygen partial pressure are diamagnetic, confirming that no FM impurities were introduced during the preparation of the films. It should be noted that FM behavior and average grains diameters upon different oxygen partial pressure have different trends. It implies that the average grains sizes are indirectly related 


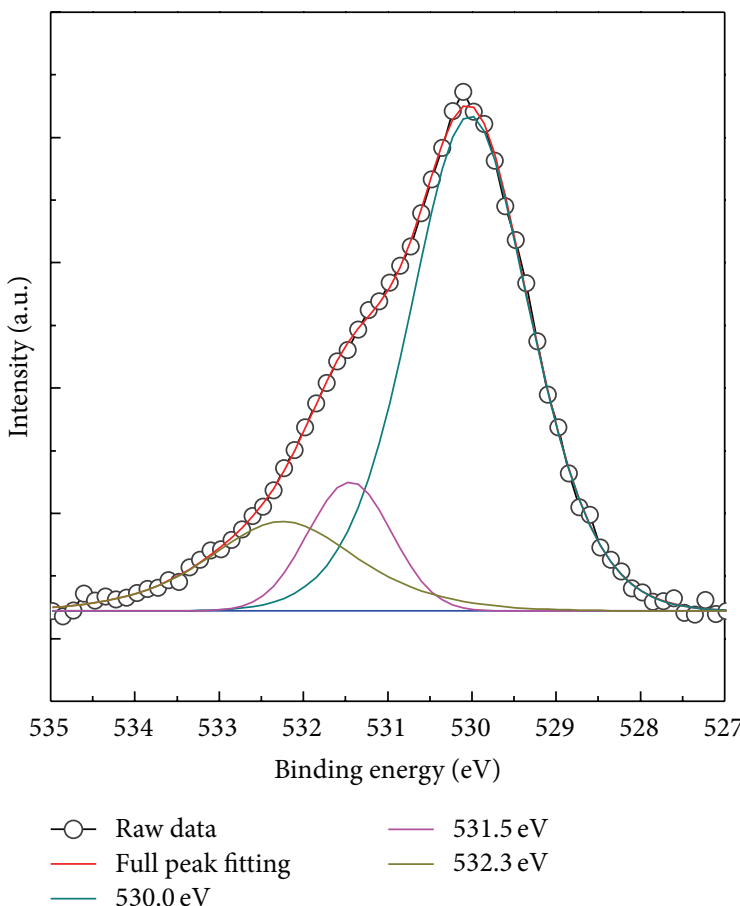

(a)

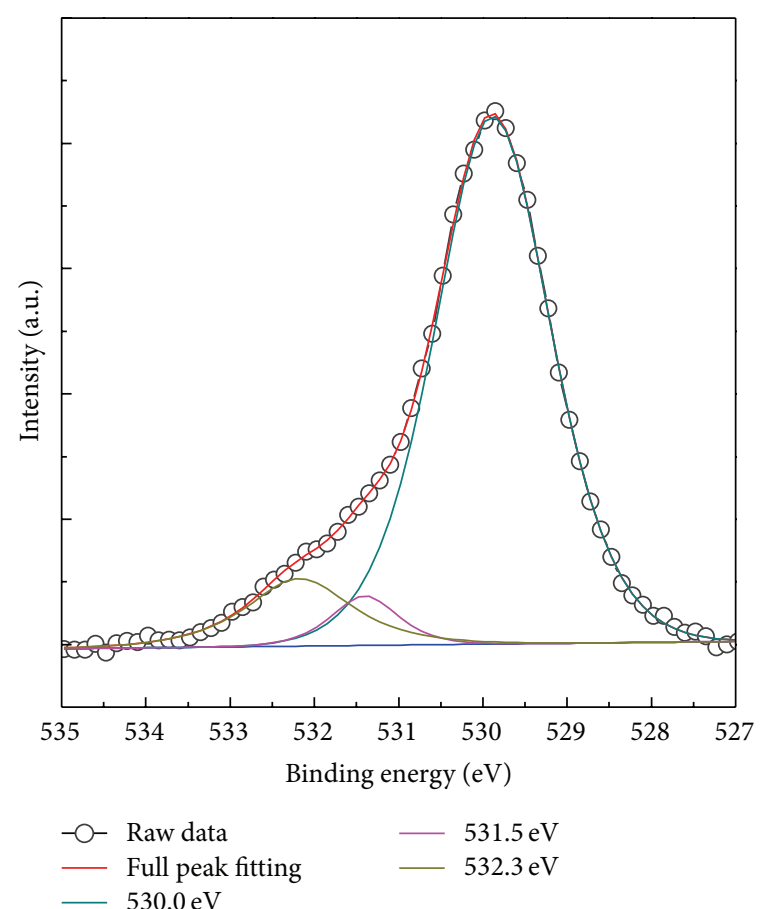

(b)

FIGURE 3: XPS data of $\mathrm{O} 1 s$ and its Gaussian-resolved component for the sample deposited under (a) $P_{\mathrm{O}_{2}}=0 \mathrm{~Pa}$ and (b) $P_{\mathrm{O}_{2}}=2 \mathrm{~Pa}$, respectively.

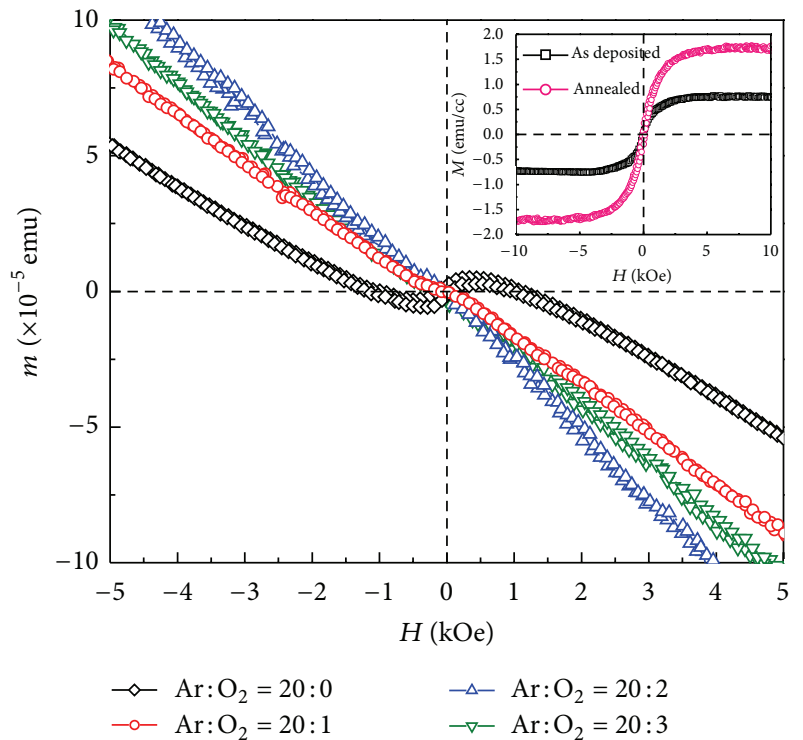

FIgURE 4: $M-H$ curves for $\mathrm{ZnO}$ thin films deposited under different oxygen partial pressure at $300 \mathrm{~K}$. Upper inset: $M-H$ curves of $\mathrm{ZnO}$ as-deposited and annealed films deposited under $P_{\mathrm{O}_{2}}=0 \mathrm{~Pa}$ at $300 \mathrm{~K}$ after the subtraction of the diamagnetic signal.

to the FM in undoped $\mathrm{ZnO}$ films. On the other hand, the measured resistivity of the samples deposited under $P_{\mathrm{O}_{2}}=$ $0 \mathrm{~Pa}$ is $6.5(2) \times 10^{4} \Omega \mathrm{cm}$ at RT.
Indeed, the origin of RT FM in undoped $\mathrm{ZnO}$ is still a controversial issue. Many hypotheses have been presented to give a reasonable interpretation for the origin of the RT FM in pure $\mathrm{ZnO}$. Since the sample deposited under $P_{\mathrm{O}_{2}}=0 \mathrm{~Pa}$ is insulators, the carrier-mediated RKKY-type model seems not to be applicable. According to previous work [23-26], the origin of the room temperature $\mathrm{FM}$ of undoped $\mathrm{ZnO}$ is due to the introduction of $\mathrm{Zn}_{i}$ and/or $V_{\mathrm{O}}$ defects rather than $\mathrm{Zn}$ vacancies $\left(V_{\mathrm{Zn}}\right)$, because formation energy of $V_{\mathrm{Zn}}$ is so high that it could not preferably form in $\mathrm{ZnO}$. The chemical states of $\mathrm{Zn}$ and $\mathrm{O}$ ions in $\mathrm{ZnO}$ samples deposited under different $P_{\mathrm{O}_{2}}$ show that $\mathrm{Zn}_{i}$ and $V_{\mathrm{O}}$ coexist in the asdeposited samples. As $P_{\mathrm{O}_{2}}$ increases, both of the $\mathrm{Zn}_{i}$ and $V_{\mathrm{O}}$ are decreasing meanwhile the FM disappears at higher $P_{\mathrm{O}_{2}}$. Thus, the $\mathrm{Zn}_{i}$ and/or $V_{\mathrm{O}}$ should contribute to the origin of $\mathrm{FM}$ in pure $\mathrm{ZnO}$ thin films. To further confirm which kind of defect plays a more important role in the origin of FM in the sample, a layer of pure $\mathrm{Zn}$ with thickness of about $70 \mathrm{~nm}$ was deposited on the $\mathrm{ZnO}$ film deposited under $P_{\mathrm{O}_{2}}=0 \mathrm{~Pa}$. Then, the sample was heated in high vacuum at $300^{\circ} \mathrm{C}$ for $10 \mathrm{~min}$. Because the diffusion of $\mathrm{Zn}$ is easier than that of oxygen [33] and there are not enough oxygen atoms from the air which can diffuse in the lattice to oxidize the diffused $\mathrm{Zn}, \mathrm{Zn}_{i}$ will generate and be trapped in the lattice, which leads to the increase in defect density of $\mathrm{Zn}_{i}$. On the other hand, magnetic measurement indicates that the saturated magnetization of annealed sample increases to $1.62 \mathrm{emu} / \mathrm{cc}$. Thus, $\mathrm{Zn}_{i}$ not $V_{\mathrm{O}}$ should be responsible for the observed weak RT FM in asdeposited sample and the significant increase of $M_{s}$ in the annealed sample. 
Theoretical calculation indicated that the level of $\mathrm{Zn}_{i}$ lies close to the bottom of the conduction band (shallow donors), which will induce strong interaction between the localized interstitial $\mathrm{Zn} 4 \mathrm{~s}$ level and the conduction band [5]. This interaction alternates the electronic structure, leading to ferromagnetic-like behavior. It should be noted that this modification of the semiconductor electronic structure can be realized in the absence of the magnetic ions. More generally, other methods inducing such kind of shallow donors will also alternate the electronic structure and result in the RT $\mathrm{FM}$, such as fabricating $\mathrm{ZnO}$ low dimensional nanoparticles with more intrinsic defects, capping with organic molecules into $\mathrm{ZnO}$ nanoparticle [29] and producing more defects by mechanical milling in $\mathrm{ZnO}$ nanoparticles [23].

\section{Conclusions}

In summary, RT FM is observed in undoped $\mathrm{ZnO}$ thin films deposited without oxygen, while other samples deposited under different $P_{\mathrm{O}_{2}}$ are all diamagnetism. After depositing a single $\mathrm{Zn}$ layer on the magnetic $\mathrm{ZnO}$ thin films and annealing the sample at high temperature, the saturated magnetization significantly increased. All results indicate that the origin of FM order in pure $\mathrm{ZnO}$ films should be related to the $\mathrm{Zn}_{i}$ defects. The shallow donor caused by $\mathrm{Zn}_{i}$ defects might modify the electronic structure of undoped $\mathrm{ZnO}$ thin films, leading to the RT FM. Our result will help to get further insight into the ferromagnetic origin in undoped $\mathrm{ZnO}$ systems.

\section{Conflict of Interests}

The authors declare that there is no conflict of interests regarding the publication of this paper.

\section{Acknowledgments}

This work was supported by the National Natural Science Foundation of China (Grant nos. 51102075, 51171056, and 51371075) and the Key Project of Science and Technology for Colleges in Hebei Province, China (Grant no. ZD2010120).

\section{References}

[1] S. A. Wolf, D. D. Awschalom, R. A. Buhrman et al., "Spintronics: a spin-based electronics vision for the future," Science, vol. 294, no. 5546, pp. 1488-1495, 2001.

[2] T. Dietl, H. Ohno, F. Matsukura, J. Cibert, and D. Ferrand, "Zener model description of ferromagnetism in zinc-blende magnetic semiconductors," Science, vol. 287, no. 5455, pp. 1019$1022,2000$.

[3] J. M. D. Coey, M. Venkatesan, and C. B. Fitzgerald, "Donor impurity band exchange in dilute ferromagnetic oxides," Nature Materials, vol. 4, no. 2, pp. 173-179, 2005.

[4] H. Gu, W. Zhang, Y. Xu, and M. Yan, "Effect of oxygen deficiency on room temperature ferromagnetism in Co doped $\mathrm{ZnO}$," Applied Physics Letters, vol. 100, no. 11, Article ID 202401, 2012.
[5] C. H. Patterson, "Role of defects in ferromagnetism in Zn1-xCoxO: a hybrid density-functional study," Physical Review B, vol. 74, no. 14, Article ID 144432, 2006.

[6] H. Liu, X. Zhang, L. Li et al., "Role of point defects in room-temperature ferromagnetism of Cr-doped $\mathrm{ZnO}$," Applied Physics Letters, vol. 91, no. 7, Article ID 072511, 2007.

[7] J. M. Baik, T. W. Kang, and J.-L. Lee, "Effects of $\mathrm{N}_{2} \mathrm{O}$ plasma treatment on magnetic properties of $(\mathrm{Zn}, \mathrm{Mn}) \mathrm{O}$ nanorods," Nanotechnology, vol. 18, no. 9, Article ID 095703, 2007.

[8] K. R. Kittilstved, W. K. Liu, and D. R. Gamelin, "Electronic structure origins of polarity-dependent high- $\mathrm{T}_{\mathrm{c}}$ ferromagnetism in oxide-diluted magnetic semiconductors," Nature Materials, vol. 5, no. 4, pp. 291-297, 2006.

[9] J. Alaria, P. Turek, M. Bernard et al., "No ferromagnetism in Mn doped ZnO semiconductors," Chemical Physics Letters, vol. 415, no. 4-6, pp. 337-341, 2005.

[10] S. Yin, M. X. Xu, L. Yang et al., "Absence of ferromagnetism in bulk polycrystalline $\mathrm{Zn}_{0.9} \mathrm{Co}_{0.1} \mathrm{O}$," Physical Review B, vol. 73, no. 22, Article ID 224408, 2006.

[11] M. Venkatesan, C. B. Fitzgerald, J. G. Lunney, and J. M. D. Coey, "Anisotropic ferromagnetism in substituted zinc oxide," Physical Review Letters, vol. 93, no. 17, Article ID 177206, p. 1, 2004.

[12] H. Pan, J. B. Yi, L. Shen et al., "Room-temperature ferromagnetism in carbon-doped ZnO," Physical Review Letters, vol. 99, no. 12, Article ID 127201, 2007.

[13] C.-F. Yu, T.-J. Lin, S.-J. Sun, and H. Chou, "Origin of ferromagnetism in nitrogen embedded ZnO:N thin films," Journal of Physics D, vol. 40, no. 21, pp. 6497-6500, 2007.

[14] Q. Xu, H. Schmidt, S. Zhou et al., "Room temperature ferromagnetism in $\mathrm{ZnO}$ films due to defects," Applied Physics Letters, vol. 92, no. 8, Article ID 082508, 2008.

[15] S. Ghoshal and P. S. Anil Kumar, "Suppression of the magnetic moment upon Co doping in $\mathrm{ZnO}$ thin film with an intrinsic magnetic moment," Journal of Physics Condensed Matter, vol. 20, no. 19, Article ID 192201, 2008.

[16] M. Kapilashrami, J. Xu, V. Ström, K. V. Rao, and L. Belova, "Transition from ferromagnetism to diamagnetism in undoped ZnO thin films," Applied Physics Letters, vol. 95, no. 3, Article ID 033104, 2009.

[17] N. H. Hong, J. Sakai, and V. Brizé, "Observation of ferromagnetism at room temperature in $\mathrm{ZnO}$ thin films," Journal of Physics Condensed Matter, vol. 19, no. 3, Article ID 036219, 2007.

[18] Z. Yan, Y. Ma, D. Wang et al., "Impact of annealing on morphology and ferromagnetism of $\mathrm{ZnO}$ nanorods," Applied Physics Letters, vol. 92, no. 8, Article ID 081911, 2008.

[19] J. B. Yi, H. Pan, J. Y. Lin et al., "Ferromagnetism in $\mathrm{ZnO}$ nanowires derived from electro-deposition on AAO template and subsequent oxidation," Advanced Materials, vol. 20, no. 6, pp. 1170-1174, 2008.

[20] L. Y. Li, Y. H. Cheng, X. G. Luo et al., "Room-temperature ferromagnetism and the scaling relation between magnetization and average granule size in nanocrystalline $\mathrm{Zn} / \mathrm{ZnO}$ core-shell structures prepared by sputtering," Nanotechnology, vol. 21, no. 14, Article ID 145705, 2010.

[21] Z. Yang, "A perspective of recent progress in $\mathrm{ZnO}$ diluted magnetic semiconductors," Applied Physics A, vol. 112, no. 2, pp. 241-254, 2013.

[22] J. M. D. Coey, K. Wongsaprom, J. Alaria, and M. Venkatesan, "Charge-transfer ferromagnetism in oxide nanoparticles," Journal of Physics D, vol. 41, no. 13, Article ID 134012, 2008. 
[23] T. L. Phan, Y. D. Zhang, D. S. Yang, N. X. Nghia, T. D. Thanh, and S. C. Yu, "Defect-induced ferromagnetism in $\mathrm{ZnO}$ nanoparticles prepared by mechanical milling," Applied Physics Letters, vol. 102, no. 7, Article ID 072408, 2013.

[24] S. Banerjee, M. Mandal, N. Gayathri, and M. Sardar, "Enhancement of ferromagnetism upon thermal annealing in pure $\mathrm{ZnO}$," Applied Physics Letters, vol. 91, no. 18, Article ID 182501, 2007.

[25] M. H. F. Sluiter, Y. Kawazoe, P. Sharma et al., "First principles based design and experimental evidence for a $\mathrm{ZnO}$-based ferromagnet at room temperature," Physical Review Letters, vol. 94, no. 18, Article ID 187204, 2005.

[26] X. Zhang, Y. H. Cheng, L. Y. Li et al., "Evidence for high- $\mathrm{T}_{c}$ ferromagnetism in $\mathrm{Zn}_{x}(\mathrm{ZnO})_{1-x}$ granular films mediated by native point defects," Physical Review B, vol. 80, no. 17, Article ID 174427, 2009.

[27] B. B. Straumal, A. A. Mazilkin, S. G. Protasova et al., "Magnetization study of nanograined pure and $\mathrm{Mn}$-doped $\mathrm{ZnO}$ films: formation of a ferromagnetic grain-boundary foam," Physical Review B, vol. 79, no. 20, Article ID 205206, 2009.

[28] N. Sanchez, S. Gallego, J. Cerdá, and M. C. Muñoz, “Tuning surface metallicity and ferromagnetism by hydrogen adsorption at the polar $\mathrm{ZnO}(0001)$ surface," Physical Review B, vol. 81, no. 11, Article ID 115301, 2010.

[29] M. A. Garcia, J. M. Merino, E. F. Pinel et al., "Magnetic properties of $\mathrm{ZnO}$ nanoparticles," Nano Letters, vol. 7, no. 6, pp. 1489-1494, 2007.

[30] B. D. Cullity, Elements of X-Ray Diffraction, Addison-Wesley Publication, New York, NY, USA, 1978.

[31] M. N. Islam, T. B. Ghosh, K. L. Chopra, and H. N. Acharya, "XPS and X-ray diffraction studies of aluminum-doped zinc oxide transparent conducting films," Thin Solid Films, vol. 280, no. 1-2, pp. 20-25, 1996.

[32] J. C. C. Fan and J. B. Goodenough, "X-ray photoemission spectroscopy studies of Sn-doped indium-oxide films," Journal of Applied Physics, vol. 48, no. 8, pp. 3524-3531, 1977.

[33] K. R. Kittilstved, D. A. Schwartz, A. C. Tuan, S. M. Heald, S. A. Chambers, and D. R. Gamelin, "Direct kinetic correlation of carriers and ferromagnetism in $\mathrm{Co}^{2+}: \mathrm{ZnO}$," Physical Review Letters, vol. 97, no. 3, Article ID 037203, 2006. 

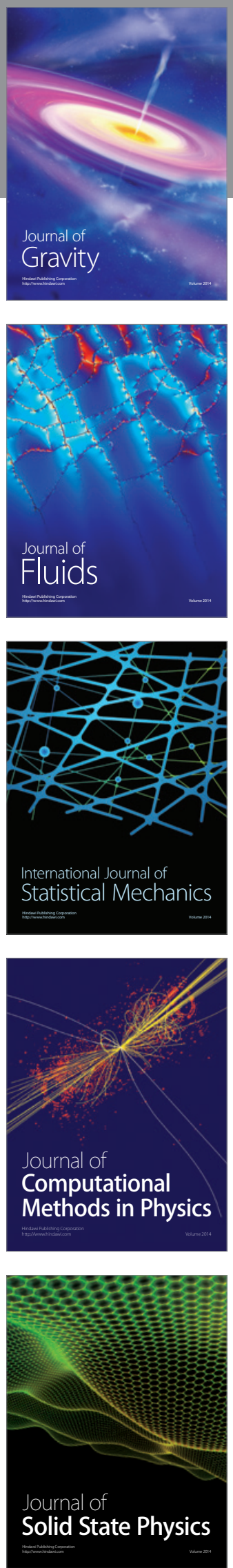

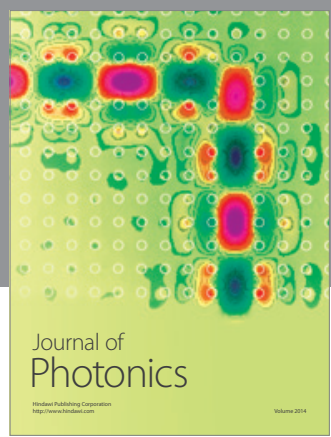

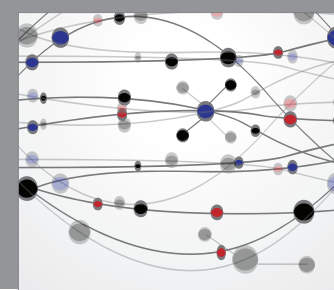

The Scientific World Journal

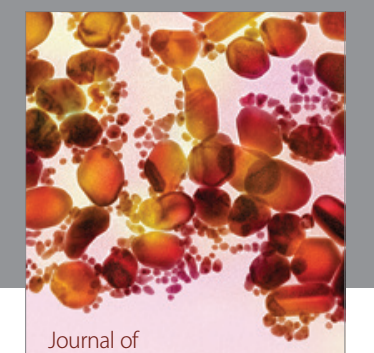

Soft Matter
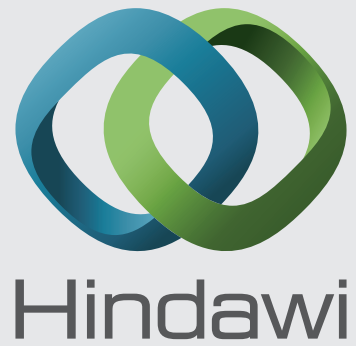

Submit your manuscripts at

http://www.hindawi.com
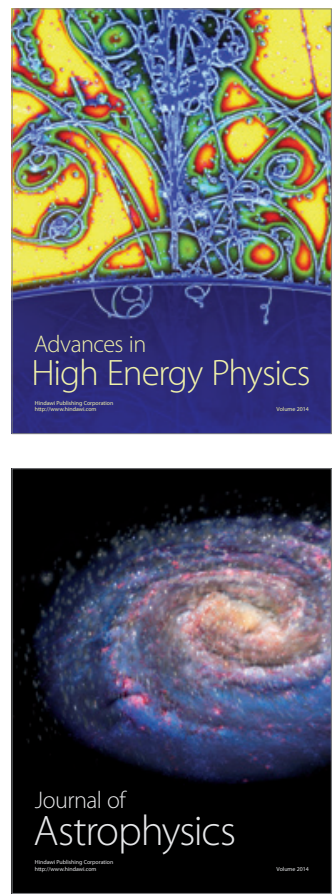
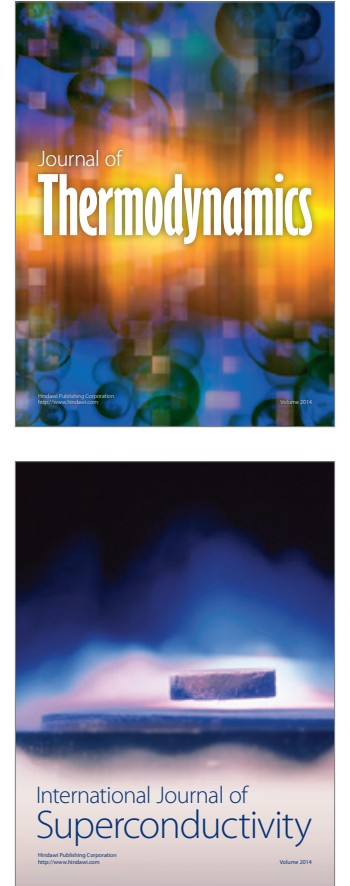
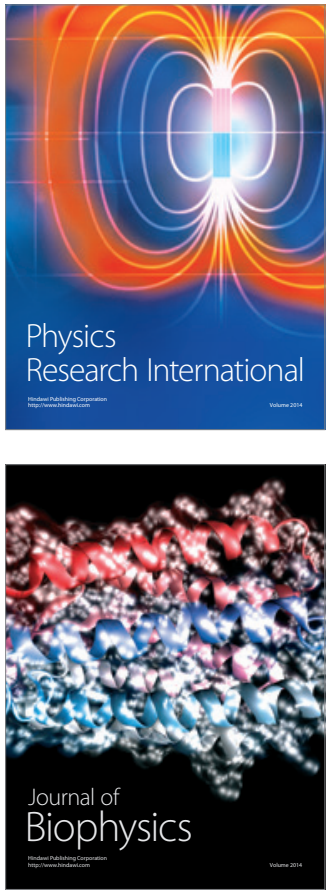
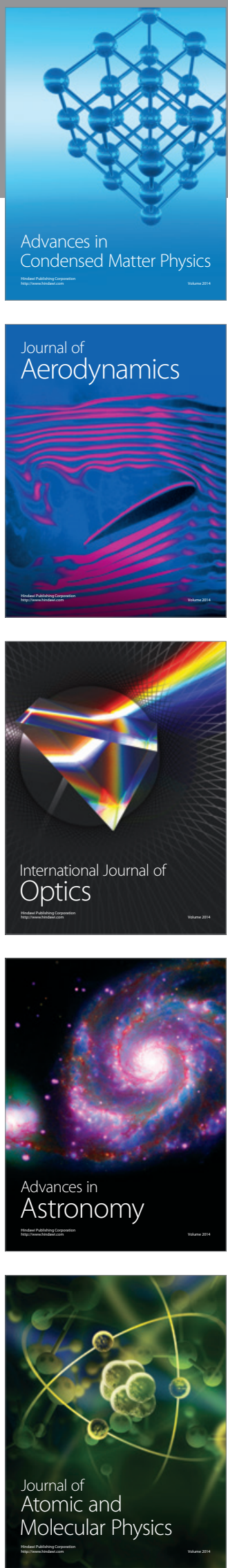